\title{
ESTIMATE THE HIGH-RESOLUTION DISTRIBUTION OF GROUND-LEVEL PARTICULATE MATTER BASED ON SPACE OBSERVATIONS AND A PHYSICAL-BASED MODEL
}

\author{
Jie Guang ${ }^{1}$, Yong Xue $e^{1,2}$, Cheng Fan ${ }^{1,3}$, Ying $L i^{1,3}$, She Lu ${ }^{1,3}$, Yahui Che $e^{1,3}$ \\ ${ }^{1}$ Key Laboratory of Digital Earth Science, Institute of Remote Sensing and Digital Earth, Chinese \\ Academy of Sciences, Beijing 100094, China \\ ${ }^{2}$ Faculty of Life Sciences and Computing, London Metropolitan University, 166-220 Holloway Road, \\ London N7 8DB, UK \\ ${ }^{3}$ University of the Chinese Academy of Sciences, Beijing 100049, China
}

\begin{abstract}
Atmospheric particulate matter estimated by using satellite data is gaining more attention due to their wide spatial coverage advantages. Here, instead of empirical statistical approach, we describe a physical-based approach that reduces the uncertainty of surface $\mathrm{PM}_{10}$ estimation from satellite data. In our approach, particulate matter mass concentration retrievals require the inclusion of optical properties of aerosol particles and meteorological parameters. We use one year of MODIS aerosol optical depth data at $550 \mathrm{~nm}$ and meteorological data to estimate surface level $\mathrm{PM}_{10}$ over China. As compared to regression coefficients obtained through simple correlation $(\mathrm{R}=0.44)$ or multiple regression $(\mathrm{R}=0.53)$ techniques, the physicalbased approach derives hourly $\mathrm{PM}_{10}$ data that compared with ground-based measurements with $\mathrm{R}=0.74$. Although the degree of improvement varies over different sites and seasons in China, this study demonstrates the potential for using physical-based approach for operational air quality monitoring.
\end{abstract}

Index Terms-Physical-based; Particulate Matter; Aerosol optical depth; Remote Sensing; China

\section{INTRODUCTION}

Atmospheric pollution due to natural and anthropogenic emissions of aerosols is a nowadays recognized serious threat to human health due to respiratory and toxic adverse health effects. $\mathrm{PM}_{10}$ or inhalable particles are particles with an aerodynamic diameter less than $10 \mu \mathrm{m}$. Over the past few decades, particulate matter air quality has become a focus of public safety campaigners in China. Continuous monitoring of the observation data, e.g., aerosol optical depth (AOD), $\mathrm{PM}_{2.5}$, and $\mathrm{PM}_{10}$, from surface stations and space satellites is important for studying the climatic and environmental effect of regional aerosol. Most current research focused on developing empirical statistical models using ground measurements of the ambient particulate and satellite derived AOD [1]. However, empirical statistical model has its limitation, which is can't be extended to other areas or historical periods. In other words, these relationships were scarce and undefined in the different regions of China, resulting in very large errors in estimating the $\mathrm{PM}_{2.5}$ or $\mathrm{PM}_{10}$ concentration based on satellite remote sensing. Besides, this relation is strictly speaking only valid for fine mode particles, e.g., $\mathrm{PM}_{2.5}$. For coarse particles, such a relationship cannot be found because of their relatively small spectral impact. To deduce information about the mass load, such retrievals work with additional assumptions about the consistency of the local aerosol or additional information from other ground or space based information about the size distribution of the aerosols, i.e., information about local aerosol model or using synergetic models [2-3]. Although the results are quite promising, those techniques are only successful for the region to which further information from ground measurements or from models are added. Besides, the retrieval accuracy is still need to improve. Here, instead of empirical statistical approach, we describe a physical-based approach that reduces the uncertainty of surface $\mathrm{PM}_{10}$ estimation from satellite data. In our approach, particulate matter mass concentration retrievals require the inclusion of optical properties of aerosol particles (such as AOD, particle sizes, the extinction efficiency) and meteorological parameters. This is reasonable because a change of meteorological parameter like the planetary boundary layer height or the humidity of the air can cause a massive change of the mass concentration.

\section{MATERIALS AND METHOD}

One year of MODerate resolution Imaging Spectroradiometer (MODIS) AOD data at $550 \mathrm{~nm}$ and meteorological data were used to estimate surface level $\mathrm{PM}_{10}$ over China by a new physical-based model.

\subsection{Remote Sensing Data}


The study region covers most of China $\left(70^{\circ} \mathrm{E}\right.$ to $140^{\circ} \mathrm{E}$, $15^{\circ} \mathrm{N}$ to $55^{\circ} \mathrm{N}$ ) and the study period is from March 1,2013 to February 28, 2014. In this study, the $10 \mathrm{~km}$ MODIS C6 AOD product retrieved by the fusion of deep blue and darktarget land algorithm at $550 \mathrm{~nm}$ (C6 MYD04_L2) and $3 \mathrm{~km}$ MODIS C6 deep blue AOD product (MYD04_3K) are used to depict detailed pollutant distribution at a high spatial resolution, as shown in Figure 1.
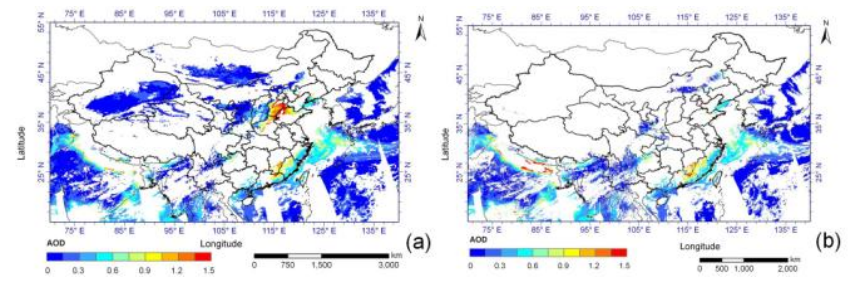

Figure 1. AOD maps of (a) C6 MYD04_L2, (b) C6 MYD04_3K at $550 \mathrm{~nm}$ of MODIS level 2 aerosol products on January 29, 2014.

\subsection{Ground Data}

Surface meteorological parameters, including relative humidity $(\mathrm{RH})$, boundary layer height $(\mathrm{BLH})$, wind speed (WS) and temperature (TEMP). RH and BLH spatial distribution of research area are as shown in Figure 2, are acquired from ERA Interim Data of The European Centre for Medium-Range Weather Forecasts (ECMWF) (http://www.ecmwf.int/).

Hourly $\mathrm{PM}_{10}$ concentration data from March 1, 2013 to February 28, 2014 are used in this study, which is released by China national environmental monitoring centre (CNEMC) (http://106.37.208.233:20035/).
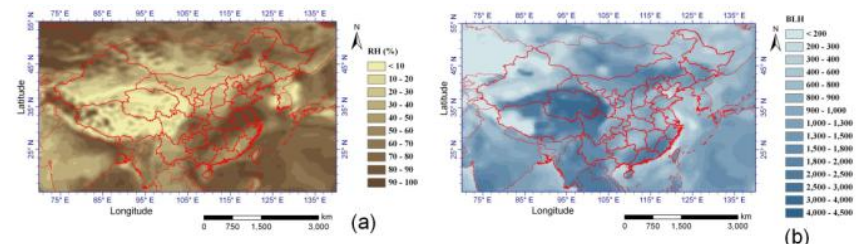

Figure 2. (a) Relative humidity (RH), (b) Boundary layer height (BLH) from ECMWF on July 1, 2013.

\section{METHOD}

Most current research focused on developing empirical statistical models using ground measurements of the ambient particulate and satellite derived AOD. However, empirical statistical model has its limitation, which is cannot be extended to other areas or historical periods. Besides, this relation is strictly speaking only valid for fine mode particles, e.g., $\mathrm{PM}_{2.5}$. For coarse particles, such a relationship cannot be found because of their relatively small spectral impact. Here, instead of empirical statistical approach, we describe a physical-based approach that reduces the uncertainty of surface $\mathrm{PM}_{10}$ estimation from satellite data. In our approach, particulate matter mass concentration retrievals require the inclusion of optical properties of aerosol particles (AOD, $\alpha, Q_{\text {ext }}$ ), physical properties of aerosol particles $\left(r_{\text {eff }}\right)$ and meteorological parameters $(R H, B L H)$ :

$$
\mathrm{PM}_{10}=f\left(\mathrm{AOD}, R H, B L H, Q_{\mathrm{ext}}, r_{\mathrm{eff}}, \alpha\right)
$$

where $Q_{\text {ext }}$ is the size-distribution integrated extinction efficiency; $r_{\text {eff }}$ represents aerosol effective radius; $\alpha$ represents Ångström- $\alpha$ exponent.

\section{RESULTS AND ANALYSIS}

\subsection{Spatial distribution of satellite-retrieved $\mathbf{P M}_{10}$}

Figure 3(a)-3(d) show the averaged satellite-retrieved $\mathrm{PM}_{10}$ concentrations, respectively, from Spring (Mar., Apr. \& May 2013) to Winter (Dec. 2013, Jan. \& Feb. 2014). Heavy pollution in Xinjiang province is caused by dust storms in Spring and Autumn. Heavy pollution in the middle and the east of China may be the result of dense industry, intense human activities, and unfavorable topography. The Yangtze River Delta, the Pearl River Delta and the Beijing-TianjinHebei region are relatively with high $\mathrm{PM}_{10}$ concentrations.
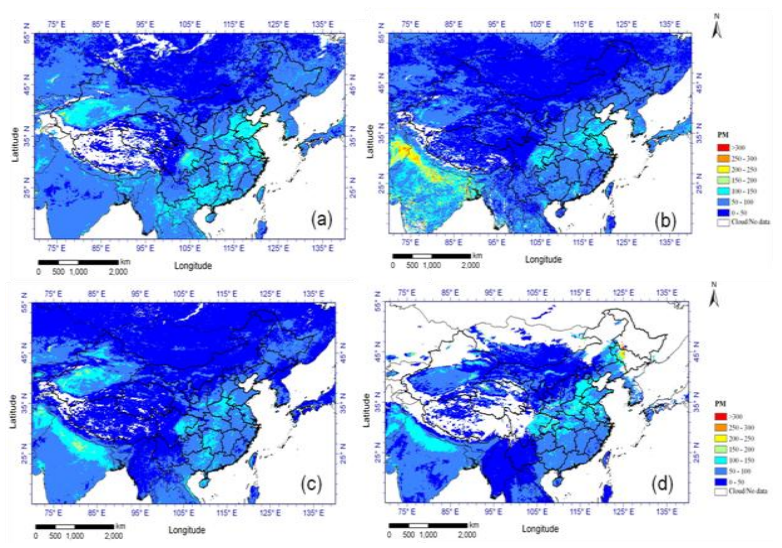

Figure 3. $\mathrm{PM}_{10}$ maps of (a) Spring (Mar., Apr. \& May 2013), (b) Summer (Jun., Jul. \& Aug. 2013), (C) Autumn (Sep., Oct. \& Nov. 2013) and (d) Winter (Dec. 2013, Jan. \& Feb. 2014) retrieved by this method.

\subsection{Capability on urban scale identification}

The area specific comparisons between ground-measured and MODIS retrieved $\mathrm{PM}_{10}$ are shown in Figure 4. The comparisons with hourly $\mathrm{PM}_{10}$ measurements at Beijing, Guangzhou, and Chengdu City are illustrated. The mean ground-measured $\mathrm{PM}_{10}$ concentrations from October 2013 
to February 2014 at the three locations are $90 \mu \mathrm{g} / \mathrm{m}^{3}, 100$ $\mu \mathrm{g} / \mathrm{m}^{3}$ and $181 \mu \mathrm{g} / \mathrm{m}^{3}$, respectively. The mean satellitederived $\mathrm{PM}_{10}$ concentrations from October 2013 to February 2014 at the three locations are $62 \mu \mathrm{g} / \mathrm{m}^{3}, 101 \mu \mathrm{g} / \mathrm{m}^{3}$ and 106 $\mu \mathrm{g} / \mathrm{m}^{3}$, respectively. Significant correlations of $0.70(\mathrm{~N}=70$, $\left.\operatorname{RMSE}=6.6 \mu \mathrm{g} / \mathrm{m}^{3}\right), 0.34\left(\mathrm{~N}=33, \mathrm{RMSE}=11 \mu \mathrm{g} / \mathrm{m}^{3}\right)$ and $0.51\left(\mathrm{~N}=19\right.$, RMSE $\left.=32 \mu \mathrm{g} / \mathrm{m}^{3}\right)$ are found at the three cities, respectively. Beijing station which located in the North of China has the best consistency when compared the ground-measured and satellite-derived $\mathrm{PM}_{10}$ concentrations. Guangzhou and Chengdu City are belong to the cloudy and rainy areas, hence satellite-derived $\mathrm{PM}_{10}$ in these areas have low accuracy may caused by the influence of high relative humidity which should correct for the effects of aerosol hygroscopic growth.
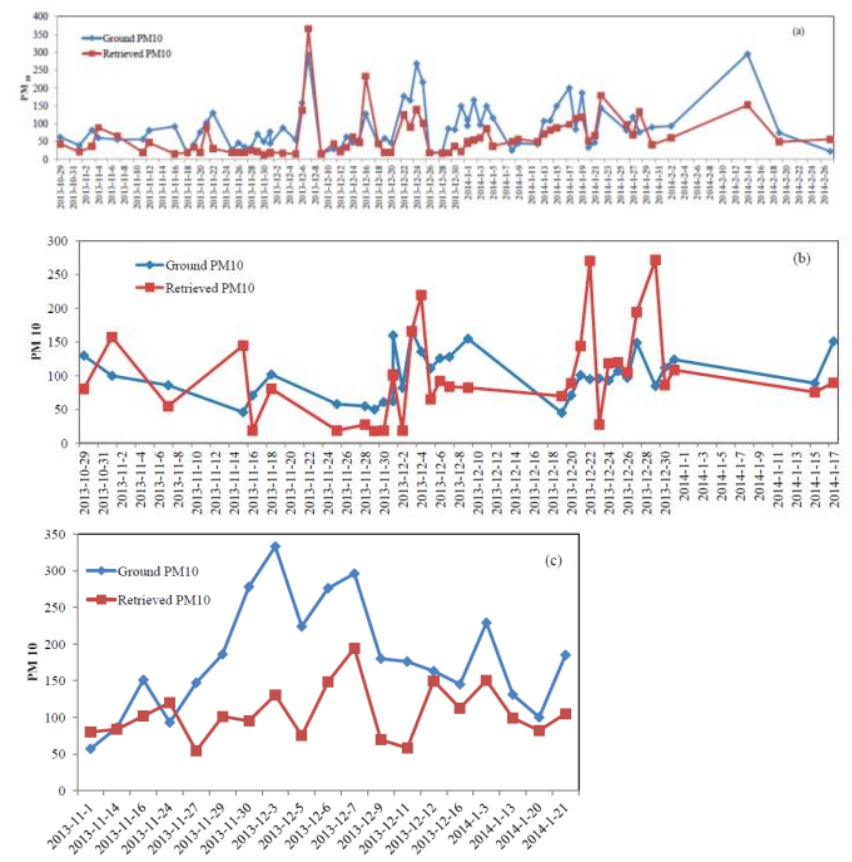

Figure 4. $\mathrm{PM}_{10}$ of (a) Beijing, (b) Guangzhou, (c) Chengdu retrieved by this method compared with ground measurements.

\subsection{Comparison of different $\mathrm{PM}_{10}$ retrieval methods}

A simple method to direct correlate $\mathrm{PM}_{10}$ and AOD was made, and the retrieved $\mathrm{PM}_{10}$ concentration on January 29, 2014 is shown as Figure 5(a). Multiple regression method correlation $\mathrm{PM}_{10}$, AOD, relative humidity, wind speed (WS) and temperature (TEMP) was also used to retrieve $\mathrm{PM}_{10}$ concentrations on January 29, 2014, which is shown as Figure 5(b). Figure 5(c) shows the retrieved $\mathrm{PM}_{10}$ concentration by the method proposed in this paper. From the maps, we can be seen that simple method can show the trend of $\mathrm{PM}_{10}$ spatial distribution, but has less accuracy. However, the multiple regression method may lead to wrong tendency as too many uncontrollable factors were introduced. The physical-based approach has both good tendency and accuracy.
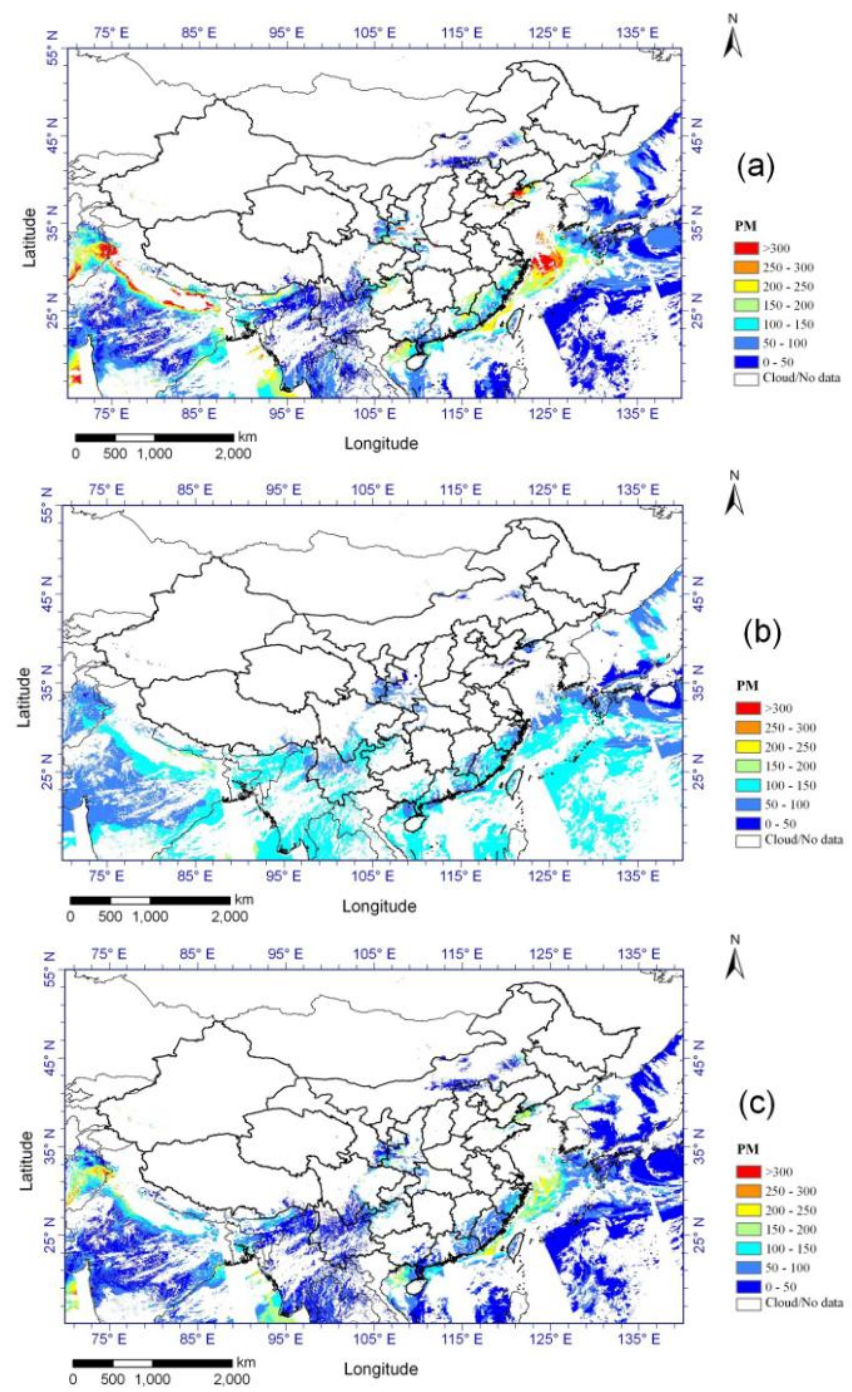

Figure 5. (a) $\mathrm{PM}_{10}$ map of China retrieved by (a) simple correlation - Method 1: $\mathrm{PM}_{10}=\mathrm{a}^{*} \mathrm{AOD}+\mathrm{b}$, (b) multiple regression - Method 2: $\quad \mathrm{PM}_{10}=\mathrm{a} 1+\mathrm{a} 2 * \mathrm{RH}+\mathrm{a} 3 * \mathrm{WS}+$ a4*TEMP+a5*AOD, (c) this method on January 29, 2014.

Ground measured $\mathrm{PM}_{10}$ concentration on January 29, 2014 of 117 ground stations were used to validate the three $\mathrm{PM}_{10}$ retrieval methods introduced above, which were shown in Figure 6. Regression coefficient (R) of Method 1 $\left(\mathrm{PM}_{10}=\mathrm{a} * \mathrm{AOD}+\mathrm{b}\right)$ is 0.44 . The regression equation is $y=$ $0.4489 x+60.142$. Regression coefficient of Method 2 $\left(\mathrm{PM}_{10}=\mathrm{a} 1+\mathrm{a} 2 * \mathrm{RH}+\mathrm{a} 3 * \mathrm{WS}+\mathrm{a} 4 * \mathrm{TEMP}+\mathrm{a} 5 * \mathrm{AOD}\right)$ is 0.53 . The regression equation is $y=-0.2935 x+97.306$. Regression coefficient of Method 3 (method proposed in this paper) is 0.74 . The regression equation is $y=0.7545 x+$ 50.67. Therefore, the physical-based approach for $\mathrm{PM}_{10}$ 
retrieval is more effective than empirical statistical model. Besides, the physical-based approach independent of the ground-measured data, so it has better space and time scalability.

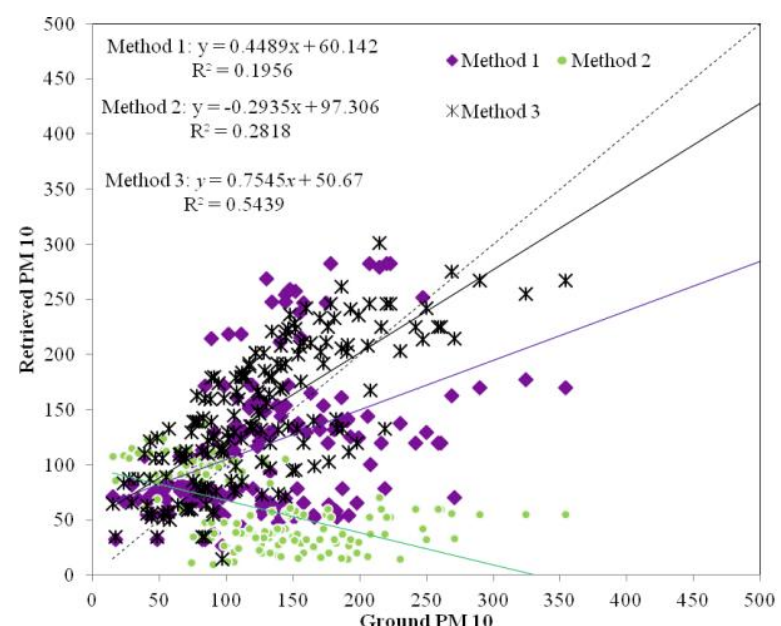

Figure 6. Satellite retrieved $\mathrm{PM}_{10}$ compared with ground measurements.

\section{CONCLUSIONS AND FUTURE WORK}

We use one year of MODIS AOD data at $550 \mathrm{~nm}$ and meteorological data to estimate surface level $\mathrm{PM}_{10}$ over China by a new physical-based model. Result shows the capacity and power of the satellite retrieval method for identifying the mean concentrations, variations, and spatial distributions of $\mathrm{PM}_{10}$ at regional and urban scales. As compared to regression coefficients obtained through simple correlation $(\mathrm{R}=0.44)$ or multiple regression $(\mathrm{R}=0.53)$ techniques, the physical-based approach derives hourly $\mathrm{PM}_{10}$ data that compare with ground-based measurements with $\mathrm{R}=0.74$. In addition, the physical-based approach independent of the ground-measured data, so it has better space and time scalability. Although the degree of improvement varies over different sites and seasons in China, this study demonstrates the potential for using physical-based approach for operational air quality monitoring. These results and analysis are useful to research and operational communities that seek to improve the use of satellite information for assessing surface $\mathrm{PM}_{10}$.

\section{ACKNOWLEDGEMENTS}

This work was supported in part by the National Natural Science Foundation of China (NSFC) under Grant 41471306 and 41590855 , and by the Ministry of Science and Technology of China under Grant 2013CB733403.
[1] A. C. Just, R.O. Wright, J. Schwartz, B. A. Coull, A. A. Baccarelli, M. M. Tellez-Rojo, E. Moody, Y. Wang, A Lyapustin, and I. Kloog, "Using High-Resolution Satellite Aerosol Optical Depth To Estimate Daily PM2.5 Geographical Distribution in Mexico City," Environmental Science \& Technology, 49, 8576$8584,2015$.

[2] G. Geng, Q. Zhang, R.V. Martin, A. Donkelaar, H. Huo, H. Che, J. Lin, K. He, "Estimating long-term PM2.5 concentrations in China using satellite-based aerosol optical depth and a chemical transport model," Remote Sensing of Environment, 166, 262-270, 2015.

[3] Y. Zhang, Z.Q. Li, "Remote sensing of atmospheric fine particulate matter (PM2.5) mass concentration near the ground from satellite observation," Remote Sensing of Environment,160, 252-262, 2015

\section{REFERENCES}

